\title{
A comunicação escrita e a falta de coerência em textos produzidos por estudantes universitários
}

\author{
Written communication and lack of coherence in texts produced \\ by university students
}

\section{Sandra Maria Leal Alves ${ }^{1}$}

Universidade Federal de Pelotas - UFPel

\begin{abstract}
Resumo: Este estudo discorre sobre textos produzidos por universitários ingressantes na universidade, a partir de uma avaliação da linguagem e do sentido que apresentam. Foram analisados 70 textos que respondiam a uma pergunta-estímulo, cuja resposta esperada era um texto de curta extensão com a opinião dos informantes sobre o assunto. As hipóteses, a priori, eram de que os textos poderiam apresentar alguns problemas com relação à linguagem e à semântica e, de fato, na totalidade do corpus, em graus variáveis, com tendência maior para problemas de sentido, as hipóteses se confirmaram.
\end{abstract}

Palavras-chave: Universitários. Textos. Linguagem. Sentido.

Abstract: The study analyzes written language use by undergraduate students entering university, in terms both of register appropriacy and coherence. Seventy texts in which an answer to a stimulus question was produced were analyzed. Based on the data, the initial hypothesis that language use by the participants would be problematic was confirmed. Actually, data analysis has shown language usage problems in the totality of the corpus, with difficulties related to written coherence being the most salient.

Keywords: university students. written text production. language use. meaning.

\footnotetext{
${ }^{1}$ Doutora em Linguística Aplicada pela Pontifícia Universidade Católica do Rio Grande do Sul/PUCRS Professora Adjunta do Centro de Letras e Comunicação da Universidade Federal de Pelotas/UFPel
} 



\section{Considerações iniciais}

O presente estudo, que se insere na área de Linguística Aplicada ao Ensino, teve por objetivo analisar aspectos relativos à construção de sentido em textos produzidos por estudantes universitários ingressantes do curso de Licenciatura em LetrasPortuguês de uma universidade pública, cujo ingresso ocorre de duas formas - Sistema de Seleção Unificada (SISU) e Programa de Avaliação da Vida Escolar (PAVE) $)^{2}$ - e são oriundos, em sua maioria, de escolas públicas.

O perfil dos alunos investigados é bastante heterogêneo - conta com jovens recém-egressos do Ensino Médio, com portadores de títulos em diferentes áreas e com pessoas que retornam aos estudos após longo tempo afastadas dos bancos escolares. Essas são variáveis que possivelmente se refletem nos textos que produzem, gerando um material rico para pesquisa no que se refere à capacidade desses alunos para construir textos cujo raciocínio lógico-semântico e conhecimentos linguísticos denotem (ou não) proficiência no uso culto da língua na modalidade escrita.

A vivência cotidiana em sala de aula, enfrentando realidades pouco animadoras no que tange ao preparo acadêmico da grande maioria dos alunos, obriga o professor a encarar o fato de os mesmos chegarem à universidade com uma grande defasagem nas habilidades para $\circ$ uso culto da língua. Essa reflexão deu origem às questões de pesquisa que nortearam este estudo: i) os problemas encontrados nos textos produzidos pelos discentes são predominantemente da esfera da linguagem?; ii) os problemas mais recorrentes são de natureza lógica, para organizar as ideias? ou iii) afetam a expressão linguística e a orientação lógicosemântica?

O corpus do estudo ${ }^{3}$ constitui-se de setenta textos de curta extensão, produzidos como resposta à

\footnotetext{
${ }^{2}$ Modalidade de ingresso na qual os alunos são avaliados ao final de cada ano do Ensino Médio e os resultados das avaliações resultam numa média aritmética classificatória.

${ }^{3}$ Coletado obedecendo os princípios da ética em pesquisa e com Termo de Consentimento Livre e Esclarecido assinado pelos participantes.
}

pergunta-estímulo "o que é ser professor?", formulada com o intuito de estimular os participantes a refletir e emitir opinião sobre o assunto.

Para sustentar teoricamente as análises, buscou-se teorias relacionadas à construção da escrita Koch (2013-2014); Koch e Elias (2012); Garcia (1996); Cançado (2012); Cegalla (2008) e Val (2016), aos aspectos cognitivos da leitura e da escrita Sternberg (2000) e Smith (2003) e ao tratamento dado pelo cérebro às questões ligadas à recepção e à produção da linguagem Capovilla e Capovilla (2004) e Vigotski (2008), entre outros. Com base nesses pressupostos teóricos sobre o tema, foram analisados os textos do corpus e encaminhadas as discussões e conclusões, sempre relativas e provisórias.

\section{Conceitos e princípios para este estudo}

Esta pesquisa, realizada com universitários ingressantes em 2016, guarda estreita semelhança com um estudo realizado por Maria da Graça Costa Val, em 1983, cujo corpus consiste em redações de vestibular para ingresso na UFMG - Universidade Federal de Minas Gerais. Desse modo, os aspectos relativos à linguagem - ortografia, pontuação, concordância verbal e nominal, regência verbal e nominal, uso de crase, etc, serão avaliados com base em Cegalla (2012) - e à textualidade - coesão, coerência, intencionalidade, aceitabilidade, situacionalidade, informatividade e intertextualidade serão avaliados com base nos critérios utilizados por Val (2016).

A análise dos textos revelou que os escritores parecem não se empenhar em corresponder ao interesse do interlocutor quanto à pertinência $e$ relevância das informações que fornecem, além de faltar a essas informações precisão, ordenação e clareza. Parece faltar cooperação por parte do escritor em relação ao leitor VAL (2016, p. 11). Para a autora, ao avaliar textos dessa natureza (produzidos sob 'encomenda' e com destinatário específico - o professor) é adequado fazer algumas perguntas: dada a situação $\begin{array}{r}\text { comunicativa, as } \\ \text { características e as disposições dos }\end{array}$ 
interlocutores e o tipo textual efetivo, essa produção linguística se mostra aceitável? Tem continuidade? Apresenta progressão? Mostrase não contraditória e bem articulada? Faz uso adequado dos recursos coesivos que servem à expressão dessas qualidades? É suficientemente clara e explicita na apresentação das informações? Comporta um mínimo de novidade que possibilite reconhecê-la como manifestação personalizada e capaz de atrair a atenção de um recebedor médio? (VAL, 2016, p.35).

O exame minucioso dos textos coletados revelou dados de certa forma surpreendentes. A princípio, tinha-se a hipótese de que seriam encontrados muitos e significativos problemas de linguagem - e esses realmente se fizeram presentes, embora numa quantidade - e gravidade - bem menor do que a esperada e com prejuízos toleráveis para a compreensão dos textos.

O que se revelou significativamente problemático foram as relações de sentido; a organização lógico-semântica das ideias. Smith faz referência a esse problema com relação à leitura, mas tal explicação parece aplicar-se também à escrita. Segundo o autor

Qualquer circunstância ou situação à qual podemos trazer uma estrutura cognitiva relevante - incluindo categorias, conjuntos de características distintivas e uma multiplicidade de relações espaciais, temporais e outras relações cognitivas - provavelmente causará confusão e perplexidade. (SMITH, 2003, p.3132)

A análise do corpus parece de fato remeter a um estado de coisas semelhante ao descrito por Smith, considerando os alunos testados. Estes produzem textos confusos, incoerentes, com ideias incompletas, que parecem não terem sido revisados após a escrita, ou, mais grave ainda, mesmo que façam uma leitura final, os alunos não percebem a fragilidade do raciocínio que desenvolveram. Não ficam confusos e perplexos com o que escreveram.

A atividade de escrita não pode ser desvinculada do pensamento - primeiro organizamos mentalmente o conteúdo a ser comunicado para depois transferi-lo para o papel. Confrontando o ponto de vista de Vigotski, de que

o pensamento verbal não é uma forma de comportamento natural e inata, mas é determinado por um processo histórico- cultural e tem propriedades e leis específicas que não podem ser encontradas nas formas naturais de pensamento e fala (2008, p.63)

com o corpus analisado, poder-se-ia pensar que os problemas detectados nos textos sejam oriundos da falta de informação, conhecimento de mundo, de seus autores. Mas, por outro lado, pensar para escrever é como pensar sobre quaisquer outros fatos e eventos do mundo. Por que, então, indivíduos que não apresentam problemas nas suas formas de interação comunicativa cotidianas têm tanta dificuldade para 'eternizar' suas comunicações na forma escrita?

A condição primordial para construir raciocínios complexos sobre algo é o conhecimento prévio que alguém tem sobre esse 'algo'. Conforme Smith

como não podemos falar ou escrever de forma competente se não sabemos o que estamos falando, também não é possível demonstrar o pensamento de qualquer modo, se não compreendemos o que é esperado que pensemos. (2003, p.38)

Há que se concordar com Smith, ao menos em parte, especialmente se o nível de exigência requerido para externar uma ideia for demasiado complexo, abstrato; mas esse não foi o caso para a construção do corpus deste estudo. Os alunos deviam responder, em um parágrafo de 8 a 10 linhas, a uma pergunta bastante simples - especialmente para alguém que escolheu ingressar num curso de Letras - "o que é ser professor?"

Os textos produzidos pelos informantes induzem a pensar que, para algumas pessoas, 0 desafio de externar pensamentos e opiniões especialmente sobre elas mesmas - é uma tarefa árdua, que nem todas têm capacidade para realizar. Falar de forma genérica e dispersa sobre o mundo, sobre as outras pessoas ou sobre fatos e eventos acontece de forma espontânea, fluida, contudo, quando a tarefa é falar sobre as próprias opiniões, crenças e desejos, ocorre uma espécie de bloqueio.

De acordo com Capovilla e Capovilla (2004, p.37), a escrita permite a reflexão sobre o próprio ato linguístico, o avanço e o aprimoramento constantes da linguagem como veículo do pensamento para o pleno desenvolvimento social e cognitivo. Desse modo, é de se esperar que um texto escrito apresente 
um pensamento coeso, coerente, livre de perturbações de sentido, uma vez que o conteúdo já passou pela instância cognitiva abstrata da criação antes de chegar ao papel; ou seja, pode ser elaborado, reelaborado e finalmente expresso. $E$ ainda, mesmo quando já expresso por meio do código escrito, pode ser analisado e reformulado pelo autor, através de um exercício de reflexão sobre o dito, não sendo, pois, desculpável a produção de textos caóticos, incompreensíveis e que não atinjam as metas comunicativas, considerando que seus produtores são estudantes universitários.

A literatura sobre a escrita fala a respeito da independência que o texto adquire com relação ao autor. Depois de escrito, o texto ganha "vida própria", espalha-se pelo mundo e pode, a qualquer tempo e em qualquer contexto, ser lido e compreendido por diferentes leitores. Porém de que textos e de que autores fala a literatura? Dos eruditos, dos cânones? Provavelmente sim, pois não há de ser dos textos da maioria dos nossos alunos, em qualquer grau de escolaridade. Nesses textos, na maioria das vezes, nós, professores de língua materna, não encontramos os elementos discursivos - tematização, rematização, concordância associativa, marcas de progressão discursiva e temática, estratégias de construção de sentido lógico, etc - minimamente necessários para que possamos encontrar efetivamente a textualidade.

Nesse sentido, Koch (2014, p.12) fala sobre a Linguística Textual ter como objeto central de estudo o texto enquanto processo, considerado como uma atividade sociocognitiva-interacional de construção de sentidos. Ou seja, a escolha dos elementos linguísticos superficiais, bem como sua organicidade estrutural, são frutos de um planejamento cognitivo prévio à escrita. Isso nos leva a pensar que o problema é mais grave, de solução mais complexa os alunos não conseguem pensar de forma lógica e organizada, e a consequência dessa incapacidade para elaborar um plano para a comunicação se reflete nos textos com os quais nos deparamos em sala de aula.

Para a psicologia cognitiva, a propriedade comunicativa da linguagem é o seu aspecto mais extraordinário. Com relação a isso, Sternberg (2000, p. 252) diz que podemos escrever o que estamos pensando e sentindo de maneira que outra pessoa possa ler e entender nossos pensamentos e sentimentos. Mas será que isso vale para todas as pessoas quando se trata de comunicação escrita? Por exemplo, os textos da maioria dos informantes deste estudo sugerem que construir conceitos abstratos (sobre as características de ser professor) não é uma tarefa simples. Parece que o fato de saberem o significado de palavras como bom e professor não os instrumentaliza para discorrer sobre bom como detentor do conhecimento, acessível, compreensivo, com domínio da didática, etc; e de professor como formador de opinião, mestre em ensinamentos, etc.

A estratégia cognitiva ascendente (ou processamento bottom up) utilizada para reconhecer os símbolos que formam a frase interrogativa "o que é ser professor?" não é representativa da causa do fraco desempenho dos alunos - eles a decodificaram corretamente. O problema parece residir no uso da estratégia cognitiva descendente (ou processamento top down) - qual seja a de, a partir desse input, derivar do conhecimento prévio argumentos que apresentem exatidão, lógica e coesividade.

Com relação às questões de linguagem, que embora não sejam as mais preocupantes, uma vez que podem ser ensinadas - diferentemente da capacidade de pensar com lógica, que tem que ser exercitada e é dependente quase que exclusivamente da vontade e da capacidade cognitiva do indivíduo para desenvolvê-la - há alguns textos que merecem nossa apreciação. Dentre os problemas mais graves e recorrentes, está a questão da estrutura externa e interna do parágrafo, o uso de conectores e sequenciadores discursivos e a pontuação.

Sobre a estrutura do parágrafo-padrão, Garcia diz que

o parágrafo é uma unidade de composição constituída por um ou mais de um período, em que se desenvolve determinada ideia central, ou nuclear, a que se agregam outras, secundárias, intimamente relacionadas pelo sentido e logicamente decorrentes dela. (1996, p.203) 
Essa noção de parágrafo de Garcia continua válida, mesmo que apareça com outros termos, em outros autores. Koch (2014) fala em organicidade estrutural; a mesma autora (2013, p.26), ao discorrer sobre produção escrita, diz que textos são resultados da atividade verbal de indivíduos socialmente atuantes, na qual estes coordenam suas ações no intuito de alcançar um fim social, de conformidade com as condições sob as quais a atividade verbal se realiza; Cançado (2012, p.21) argumenta que todas as línguas dependem de palavras e de sentenças dotadas de significado: cada palavra e cada sentença estão convencionalmente associadas a, pelo menos, um significado. Ou seja, um parágrafo é uma interrelação não aleatória de ideias; parte de um tópico que pode se desenvolver tanto a partir de um raciocínio dedutivo - do geral para o particular quanto indutivo - do particular para o geral, desde que apresente logicidade de conteúdo.

Ainda sobre manutenção temática e coerência, Koch diz que

Para construir um texto coerente é necessário que todos os seus enunciados sejam relevantes para a manutenção do tema em desenvolvimento. Uma das formas de garantir isso é o uso de termos que pertençam a um mesmo campo lexical ou, em termos cognitivos, que façam parte de um mesmo conjunto de conhecimentos de mundo (modelo cognitivo) que temos representado na memória. (2012, p.176)

Com relação à pontuação, embora não seja possível estabelecer normas rigorosas, esta deve estar a serviço, na escrita, especialmente da desambiguação; do estabelecimento do sentido de cada frase; de cada 'ilha' de sentido. Ela é um substituto eficaz para marcar os traços suprassegmentais da fala, assinalando pausas, ênfases e inflexões CEGALLA (2012, p. 428).

Acredito que os achados teóricos até aqui expostos são suficientes para corroborar os exemplos do corpus; por isso passemos a analisar e comentar alguns deles.

\section{Análises e discussões}

Produções textuais de escritores movidos pelas contingências circunstanciais, de modo geral, são prejudicadas em aspectos como intencionalidade, situacionalidade e informatividade em razão de esses escritores/alunos não terem, de forma efetiva e espontânea, a intenção de falar algo a seu interlocutor compulsório. Todavia isso não impede que os escritores lancem mão de suas vivências, de seus conhecimentos prévios sobre o tema, para emitirem suas opiniões, mesmo considerando a condição de produção artificial; especialmente no caso do corpus deste estudo, para o qual não havia pressão avaliativa ou classificatória.

Para não tornar a leitura deste artigo cansativa, optou-se por apresentar, de forma bastante didática, alguns textos mais significativamente representativos dos diferentes tipos de problemas detectados ${ }^{4}$. Vejamos algumas respostas ${ }^{5}$ dos informantes distribuídas em sete categorias envolvendo aspectos de coesão e coerência. Os problemas relativos à expressão linguística serão apenas identificados na sequência da discussão semântica.

\section{I - Problemas de continuidade}

Texto 22

Num mundo tudo se aprende muito cedo e muito rápido, a globalização em si facilita o acesso a questões que qualquer pessoa pode ter, sem nenhum estudo prévio.

Escolher a licenciatura é não ser egoísta, e dividir todo o seu conhecimento e técnica de aprendizagem, e ao mesmo tempo estar sempre pronto para receber mais conhecimento.

Este é um ramo honroso, pois alguém que escolhe para sua vida formar pessoas, merece todo o respeito e admiração da sociedade.
Texto 49
Trata-se de uma profissão maravilhosa, a qual desejo seguir, propagar o conhecimento e a experiência que já possuo e adquirir ainda mais, não só em aula, no campus da faculdade, mas na vida pessoal também.
Decidi seguir essa bela carreira, pois me sentirei alegre em dar aula e também aprender trabalhando.
Ser professor é compartilhar sabedoria, contribuindo para a construção da sociedade, para a formação de cidadãos que "pensam", sem deixar de lado a atenção e o carinho. Isso me fascina.

\footnotetext{
${ }^{4}$ Tenho consciência de que os leitores terão a sensação de que os exemplos podem ser trocados de categoria sem que isso prejudique a descrição do problema. A escolha obedeceu a uma gradação que os classificou como mais adequados para serem inseridos em um ou outro aspecto em discussão.

${ }^{5}$ Os exemplos foram transcritos sem nenhuma correção prévia e escolhidos de forma aleatória.
} 
Texto 57

É uma tarefa difícil e prazerosa ao mesmo tempo, conseguir transmitir sabedoria, conseguir atenção de seus alunos. Hoje os professores procuram elaborar aulas que despertem o interesse do aluno, porque a aula pode ficar cansativa, acaba formando grupos de conversa e bagunça. E também o tempo de dedicação para elaborar aulas e provas.

Esses exemplos mostram textos descontínuos de modo flagrante - e por isso, também, completamente desarticulados; constituem-se de um agrupamento de períodos em que não há uma ideia nuclear (GARCIA,1996) em torno da qual ocorre o desenrolar de um raciocínio lógico. Não ocorre a retomada através de elementos coesivos no decorrer do discurso de modo a permitir ao leitor entendê-los como uma unidade semântica. São sequências que tratam, em cada período, de um assunto diferente, o que os torna, em termos de coerência (sentido), não textos (VAL, 2016). Constituem amostras de raciocínios fragmentados, como se 0 escritor escrevesse "o que the vem à cabeça" sobre o tema.

Com relação à linguagem, nos três exemplos observam-se problemas de pontuação que não prejudicam o entendimento.

\section{II - Problemas de progressão (circularidade)}

Texto 35

Diante de tantas opções de profissões, nos deparamos com uma das carreiras mais importantes: a de professor. Para ser um bom mestre é preciso ter compromisso com o ensino, bem como fazer uso da paciência e do dom de transmitir seus conhecimentos para os aprendizes. Ser professor, independente da disciplina de atuação, é ser base não só para a educação indispensável dos alunos, mas também para as demais profissões. Portanto, ser professor é ser o caminho para a aprendizagem e peça fundamental para a construção de um mundo melhor.

\section{Texto 45}

Ser professor vai muito além daquela ideia de sala de aula, quadro e chamada. Um professor ensina uma nação inteira. Todo e qualquer profissional passa pelas mãos do professor. Ser professor é dedicar-se totalmente ao seu aluno passando para ele o máximo de seu conhecimento tendo consciência que de dentro da sua sala se formam excelentes profissionais e ficar extremamente feliz com o sucesso de cada um deles.

Texto 61

Ser professor é ser portador do conhecimento, mesmo com todas as formas e fontes de informação, ensina diferente, de jeito único. Cada professor é de um jeito, forma opiniões e ideias, traduz as dificuldades e a falta de entendimento. Professor é fonte, é luz, que ensina, conhece e aprende.

A progressão temática é a contrapartida da repetição, da circularidade, e é uma condição importante para o estabelecimento da coerência textual. Nos exemplos acima, percebe-se que as relações entre o dado e o novo (VAL, 2016), que são essenciais para o desenvolvimento do tópico, não ocorrem, o que gera pobreza de acréscimos semânticos. Os comentários são tautológicos e não trazem nenhuma informação nova. A progressão resulta prejudicada pela falta de articuladores discursivo-argumentativos, em que o segundo argumento toma o primeiro como tema, com o fim de justificá-lo ou melhor explicá-lo; contrapor-lhe ou adicionar-Ihe argumentos; (...) $(\mathrm{KOCH}, 2014)$.

Os exemplos não apresentam problemas de linguagem relevantes.

\section{III - Problemas de não contradição}

Texto 42

Atualmente ser professor não passa de ser um profissional como outro qualquer, que realiza um trabalho em troca de remuneração. Entretanto a escolha de ser um educador é algo muito mais profundo, uma vez que transmitir conhecimento é uma das poucas coisas que se pode fazer para transformar 0 ser humano e, consequentemente, a sociedade. Ser professor é mudar, por pouco que seja, as pessoas.

\section{Texto 53}

$\mathrm{Na}$ minha opinião ser professor é ter a oportunidade de levar o aluno a ver o mundo com outros olhos e também junto dele perceber novas experiências. Ser capaz de nesta relação trocar e receber.

Ser professor é uma tarefa difícil, nada que não possa ser enfrentado com amor e dedicação.

É fazer milagres dentro de uma estrutura que não corresponde mais ao anseio do educando.

Mas enfim, é sonhar com uma nova forma de ensinar e aprender.

Texto 56

A tarefa de um professor é ensinar seus alunos a olhar muito além da aprendizagem, pois adquirir conhecimentos é um processo natural na formação de um indivíduo, enquanto que, absorver esses conhecimentos não é tão fácil.

Sendo assim, o professor com suas qualificações, fará sua tarefa de tal maneira que consiga transmitir conhecimentos e levar 
seus alunos a reconhecerem a importância dos mesmos no seu agir na sociedade. Outro fator que é necessário na ação de um professor é, na prática de suas funções, ser exemplo de ética em seus relacionamentos sociais. $\mathrm{O}$ falar, o ensinar e o agir devem estar em harmonia e equilíbrio.

A não contradição textual deve ser observada tanto no cotexto quanto nas relações do texto com o mundo ao qual ele se refere. A regra básica para atender esta característica é o respeito a princípios lógicos elementares; ou seja, não se pode afirmar A e o contrário de $A$, seja de forma explícita seja de forma implícita (VAL, 2016). E essa proibição se aplica não só aos itens da superfície textual (coesão), mas também à estrutura profunda, relacionada aos conceitos (coerência).

O texto (42), nos dois primeiros períodos, apresenta duas afirmações contraditórias - ser professor não passa de ser um profissional como outro qualquer e ser um educador é algo muito mais profundo -, e, a menos que se entenda que os vocábulos professor e educador têm significados diferentes dentro do contexto 'ensino', esta passagem apresenta problema de sentido.

Em (53), tem-se um período - Ser professor é uma tarefa difícil, nada que não possa ser enfrentado com amor e dedicação - que se torna contraditório para o leitor, provavelmente, pela ausência de um conector adversativo entre o tema e o rema. Esta passagem exige do leitor cooperação para que adquira sentido (VAL, 2016, p.11), em razão da não explicitude do conectivo.

No exemplo (56), percebe-se, mais uma vez, problema com o significado de vocábulos. $\mathrm{Na}$ passagem adquirir conhecimentos é um processo natural na formação de um indivíduo, enquanto que, absorver esses conhecimentos não é tão fácil, para entender o propósito comunicativo do escritor, é preciso que o leitor interprete adquirir e absorver com sentidos diferentes dentro do mesmo contexto aprendizagem.

Os problemas de linguagem não são significativos para a compreensão do texto, excetuando-se a falta do conectivo que gera a contradição em (53).
IV - Problemas de articulação

Texto 10

Acredito que ser professor e uma grande tarefa. Tarefa de despertar, em cada educando, um olhar crítico sobre os fatos da vida. É saber ensinar a arte do voo, enquanto tantos e tantas ainda acreditam no poder opressor das gaiolas. É sonhar com um país melhor, com dias melhores onde a educação seja o motor para o desenvolvimento de um outro Brasil. Ser professor é deixar que os educandos sejam. Ser professor é ser!

Texto 62

Professor, nada mais é que um artista. Ele prepara pessoas para o mundo, ensinamentos, lições, conselhos, da qual só um professor com sua experiência é capaz de dar. Existem profissionais muito renomados: Médicos, advogados, engenheiros etc, mas nenhum deles seriam o que são, se antes não tivessem passado por um professor. Concluo que professor é um ser único, capaz de ajudar a todos com seus conhecimentos e experiência.

Texto 66

Ser professor é padecer com os livros no paraíso.

É gostar muito do que faz e estar sempre disponível a aquisição de novos conhecimentos.

O professor não pode se acomodar jamais e deve ter consciência de que enfrentará muitos problemas em sua jornada.

Crescer com os alunos e colegas de professor e não reclamar dos salários.

Afinal, tudo isto, faz parte da vida de um professor.

Esse requisito refere-se à maneira como os fatos e conceitos apresentados no texto se encadeiam, como se organizam, que papel exercem uns com relação aos outros (VAL, 2016). O texto (10) apresenta uma sequência de orações predicativas para qualificar a função de professor que transita entre o concreto e o abstrato sem marcadores linguísticos para definir os conceitos que o escritor considera objetiva ou metaforicamente; as ideias articulam-se numa espécie de "viagem" que desorienta o leitor.

Os exemplos (62) e (66) não fogem desse padrão, mas acresce-se a isso o problema de fragmentação estrutural (10 e 66), que transforma o texto numa lista mal organizada de tópicos. Os três textos apresentam sérios problemas de encadeamento das ideias, que prejudicam a sequenciação textual $(\mathrm{KOCH}, 2012)$ e, 
consequentemente, a construção do sentido por parte do recebedor. Não se percebe estratégias de referenciação anafórica que possibilitem formar cadeias coesivas mais longas $(\mathrm{KOCH}, 2013)$, unindo o dado e o novo; provavelmente porque não há informações novas, apenas afirmações não desenvolvidas.

Sobre a linguagem, o maior prejuízo tem origem na ausência de articuladores discursivos e ainda, com menor relevância, percebem-se problemas na pontuação, no uso de maiúsculas e na concordância verbal.

\section{$\mathrm{V}$ - Problemas de informatividade}

Texto 26

Ser professor é, antes de tudo, ser um intermédio entre aluno e o conhecimento.

$\mathrm{O}$ ato de lecionar é transmitir e ensinar conteúdo, questionar e incentivar o aluno a buscar cada vez mais conhecimento.

Isto é, sem dúvida nenhuma, uma imensa responsábilidade atribuida ao professor, pois o mesmo não deve apenas distribuir conteúdo desvairadamente aos seus alunos, e sim, deve instigar os alunos a possuirem mais interesse por sua materia e por conhecimento em geral.

Portanto, o professor é fundamental para uma exata transmissão de conhecimento e conteudos.

\section{Texto 30}

Hoje em dia, mais do que nunca, professor é um canal de conhecimento. Em boa parte do tempo, muito mais do que um canal que transmite apenas sua área de conhecimento, mas sim, o conhecimento como um todo.

O professor do século XXI precisa ser a mudança, e formar muito mais do que alunos, mas cidadãos que virão fazer a diferença na sociedade. Em resumo me atrevo a dizer, professor é ser o futuro.

\section{Texto 32}

Ser professor é ter a capacidade de dominar uma área, e ainda por cima ensinar a mesma. O professor é um símbolo do conhecimento, até porque propaga-o. Uma das mais nobres profissões, e ainda assim uma das mais injustiçadas. Seja por salarios péssimos, indisciplina, ou qualquer outra razão.

Os três exemplos acima são esvaziados de informações que possam acrescentar conhecimento; não trazem conteúdo novo, que surpreenda o leitor.
Discorrem sobre ideias previsíveis, sem a presença de intertextualidade - que revele a relação entre seu interior e seu exterior, exterior esse do qual fazem parte outros textos com os quais ele dialoga ( $\mathrm{KOCH}, 2013)$ - e originalidade.

Com relação à linguagem, o exemplo (26) apresenta graves problemas de acentuação; e em todos os exemplos percebem-se alguns problemas de pontuação. Há, ainda, problemas de impropriedade vocabular - intermédio e desvairadamente em (26), de colocação pronominal e oralidade - e ainda por cima - e no uso da conjunção coordenativa alternativa repetida 'seja...seja', em que ocorre a mistura incorreta com 'ou...ou' - Seja por salarios péssimos, indisciplina, ou qualquer outra razão - em (32).

VI - Problemas de generalizações (uso de chavões)

Texto 39

A profissão de educador é algo extremamente importante para a formação das pessoas, tanto profissional e intelectualmente, como em questões pessoais. É o professor que participa ativamente de inúmeros passos importantes na vida do aluno, desde 0 aprender a ler e escrever nos primeiros anos, até a formação de um profissional. Assim sendo, o papel de um professor é imensurável. Contudo, na sociedade atual, este importante profissional não recebe 0 devido valor, tanto em questões salariais, bem como em questões pessoais, sofrendo assim, com a falta de respeito e de estima por parte dos alunos.

Texto 44

Ser professor é saber conhecer e compreender todos seus alunos, fazer mais que ensinar: ensinar de um jeito diferente. Ensinar de um jeito que permita a todos, uma espetacular forma de aprender. O professor é como um pai ou uma mãe, o professor entende, ensina, compreende, ouve, mostra, ajuda e até ampara. Acredito que, quem escolhe seguir está jornada, precisa de um olhar sábio, precisa saber exatamente seu futuro papel, podendo assim, fazer a diferença.

\section{Texto 67}

Transmitir seu conhecimento para alguém em formação e servir de degrau para o crescimento do aluno. O professor é a peça fundamental para que a evolução da raça humana não pare.

Estes três últimos exemplos também apresentam problemas de informatividade, mas de natureza diferente dos observados no item V. Nestes 
encontram-se raciocínios repletos de clichês e estereótipos, com alto nível de previsibilidade e de afirmações sobre o óbvio (VAL, 2016), por isso não despertam o interesse do leitor.

Embora não contenham problemas de linguagem e de coesão e coerência significativos, são avaliados como textos de má qualidade com relação ao seu potencial informativo, o que desencoraja os leitores a investirem tempo neles.

Encerro a seção com uma citação de Pinker (2016, p. 23), na qual ele fala sobre bons escritores. Diz o autor: essa competência pode não ter se originado nos manuais de estilo, mas deve ter vindo de algum lugar. Esse lugar é a escrita de outros escritores. Bons escritores são leitores ávidos. Pinker postula que a leitura é essencial para enriquecer 0 vocabulário, conhecer expressões idiomáticas, elaborar truques retóricos e criar sensibilidade para organizar ideias que ora se combinam, ora se repelem, numa dança semântica que, segundo ele, é difícil de ensinar.

\section{Considerações finais}

No dizer de Garcia (1996), aprender a escrever é, em grande parte, se não principalmente, aprender a pensar, aprender a encontrar ideias e concatenálas. Como educadora, também acredito nisso; acredito que não basta conhecer as regras gramaticais (grafia, pontuação, sintaxe, etc), pois embora seja uma condição necessária não é suficiente para a produção de textos coesos, coerentes, com argumentos consistentes e logicamente organizados.

Considerando os exemplos mostrados no corpo deste trabalho, que são uma amostra fiel da totalidade do corpus, percebe-se a dificuldade que seus autores apresentam para organizar cognitivamente raciocínios lógico-semânticos, pelo menos na forma escrita culta. $E$ isso é preocupante numa sociedade em que tal capacidade é vista como meio de ascensão profissional e social. Com a evolução da ciência sobre o modo como aprendemos e armazenamos o conhecimento, especialmente em áreas como a psicolinguística, a neurolinguística e a psicologia cognitiva, é chegada a hora de os programas de ensino acrescentarem a seus conteúdos essas novas descobertas com o objetivo de instrumentalizar os professores. Existem modernos métodos de ensino que visam estimular o raciocínio lógico-cognitivo do aluno, incluindo-se modos de usufruir da inteligência emocional para melhorar o desempenho intelectual.

Os textos do corpus, a exemplo dos demais textos que recebemos de nossos alunos, salvo raras exceções, constituem-se num amontoado de frases mal redigidas, mal estruturadas; são uma coletânea de palavras mal escolhidas - às vezes também mal escritas -, organizadas sem um propósito claro de comunicação. O problema é grave porque parece que os alunos, além de não saberem como dizer, também não tem o que dizer; como consequência, temos textos que não cumprem com a sua função comunicativa. Certamente que para esses escritores falta o hábito da leitura e o treino da escrita, o que pode - e deve - ser estimulado através de novas metodologias de ensino.

O sentimento que tenho hoje, ao ler os textos da maioria de meus alunos, é que ler e escrever está fora de moda; pensar antes de falar/escrever também, contrariando o que diz Pinker (2016). Por outro lado, sei que não devemos desistir, e a fórmula para mudar esse quadro desanimador passa pelas nossas práticas em sala de aula. A exigência da leitura e da escrita deve voltar aos planos de ensino, por mais penoso que isso possa parecer ao aluno e por mais que onere o nosso fazer diário.

\section{Referências}

CANÇADO, Márcia. Manual de semântica: noções básicas e exercícios. São Paulo: Contexto, 2012.

CAPOVILLA, Fernando. C. \& CAPOVILLA, Alessandra. G. S. O desafio da descontinuidade entre a língua de sinais e a escrita alfabética na educação bilíngue do surdo congênito. In: RODRIGUES, C. \& TOMITCH, L. M. B. et al. Linguagem e cérebro humano: contribuições multidisciplinares. Porto Alegre: ARTMED, 2004. 
CEGALLA, Domingos P. Novíssima gramática da língua portuguesa. 48 ed.. São Paulo: Companhia Editora Nacional, 2008. 4ª reimpressão, 2012

GARCIA, Othon M. Comunicação em prosa moderna. 17 ed. Rio de Janeiro: Fundação Getúlio Vargas, 1996.

$\mathrm{KOCH}$, Ingedore V. \& ELIAS, Vanda M. Ler e escrever: estratégias de produção textual. São Paulo: Contexto, 2012.

$\mathrm{KOCH}$, Ingedore V. O texto e a construção dos sentidos. São Paulo: Contexto, 2013.

\author{
As tramas do texto. São Paulo: Contexto, \\ 2014. \\ PINKER, Steven. Guia de escrita. São Paulo: \\ Contexto, 2016. \\ SMITH, Frank. Compreendendo a leitura: uma análise \\ psicolinguística da leitura e do aprender a ler. \\ Porto Alegre: ARTMED, 2003. \\ STERNBERG, Robert J. Psicologia cognitiva. Porto \\ Alegre: Artes Médicas Sul, 2000. \\ VAL, Maria da Graça C. Redação e textualidade. 4 \\ ed. São Paulo: Martins Fontes, 2016. \\ VIGOTSKI, L. S. Pensamento e linguagem. São \\ Paulo: Martins Fontes, 2008. Augusto Leuba \\ Salum e Ana Lucia Franco. São Paulo: Cultrix, \\ 2012. 296p.
}

\section{COMO CITAR ESSE ARTIGO}

LEAL ALVES, Sandra Maria. A comunicação escrita e a falta de coerência em textos produzidos por estudantes universitários. Signo, Santa Cruz do Sul, v. 42, n. 75, dez. 2017. ISSN 1982-2014. Disponível em: $<$ https://online.unisc.br/seer/index.php/signo/article/view/9580>. Acesso em:

doi:_http://dx.doi.org/10.17058/signo.v42i75.9580. 